\title{
A meta-analysis of randomized controlled trials of azilsartan therapy for blood pressure reduction
}

\author{
Hisato Takagi, Yusuke Mizuno, Masao Niwa, Shin-nosuke Goto and Takuya Umemoto for the ALICE \\ (All-Literature Investigation of Cardiovascular Evidence) Group
}

\begin{abstract}
Although there have been a number of azilsartan trials, no meta-analysis of the findings has been conducted to date. We performed the first meta-analysis of randomized controlled trials of azilsartan therapy for the reduction of blood pressure (BP) in patients with hypertension. MEDLINE, EMBASE and the Cochrane Central Register of Controlled Trials were searched from the beginning of the records through March 2013 using web-based search engines (PubMed and OVID). Eligible studies were prospective randomized controlled trials of azilsartan (including azilsartan medoxomil) vs. any control therapy that reported clinic or 24-h mean BP as an outcome. For each study, data for the changes from baseline to final clinic systolic BP (SBP) and diastolic BP (DBP) in both the azilsartan group and the control group were used to generate mean differences and $95 \%$ confidence intervals (Cls). Of 27 potentially relevant articles screened initially, 7 reports of randomized trials of azilsartan or azilsartan medoxomil therapy enrolling a total of 6152 patients with hypertension were identified and included. Pooled analysis suggested a significant reduction in BP changes among patients randomized to $40 \mathrm{mg}$ of azilsartan vs. control therapy (clinic SBP: $-4.20 \mathrm{~mm} \mathrm{Hg} ; 95 \% \mathrm{Cl}$ : -6.05 to $-2.35 \mathrm{~mm} \mathrm{Hg} ; P<0.00001$; clinic DBP: $-2.58 \mathrm{~mm} \mathrm{Hg} ; 95 \% \mathrm{Cl}:-3.69$ to $-1.48 \mathrm{~mm} \mathrm{Hg} ; \boldsymbol{P}<0.00001 ; 24-\mathrm{h}$ mean SBP: $-3.33 \mathrm{~mm} \mathrm{Hg} ; 95 \% \mathrm{Cl}:-4.74$ to $-1.93 \mathrm{~mm} \mathrm{Hg} ; \boldsymbol{P}<0.00001 ; 24-\mathrm{h}$ mean DBP: $-2.12 \mathrm{~mm} \mathrm{Hg} ; 95 \% \mathrm{Cl}:-2.74$ to $-1.49 \mathrm{~mm} \mathrm{Hg} ; \boldsymbol{P}<0.00001)$. In conclusion, azilsartan therapy appears to provide a greater reduction in BP than control therapy in patients with hypertension.
\end{abstract}

Hypertension Research (2014) 37, 432-437; doi:10.1038/hr.2013.142; published online 10 October 2013

Keywords: azilsartan; meta-analysis; randomized controlled trial

\section{INTRODUCTION}

Azilsartan (Azilva) or azilsartan medoxomil (Edarbi; Ipreziv) is an orally administered angiotensin II receptor type 1 (AT1) blocker (ARB) used in the treatment of adults with essential hypertension. Azilsartan medoxomil is a prodrug that, after oral administration, undergoes rapid hydrolysis in the gastrointestinal tract to the bioactive moiety azilsartan before systemic absorption, ${ }^{1}$ and it was recently approved in the Europe and the United States of America for the treatment of patients with essential hypertension aged $\geqslant 18$ years. In Japan, the drug is available as the active metabolite (azilsartan), which differs from the compound licensed in Europe and the United States of America (azilsartan medoxomil). In terms of its AT1 blockade activity, azilsartan is more potent in vitro than several other comparable ARBs. ${ }^{2}$ Accordingly, azilsartan would be expected to show better antihypertensive efficacy than these ARBs. Although there have been a number of azilsartan trials, no metaanalysis of the findings has been conducted to date. We performed the first meta-analysis of randomized controlled trials of azilsartan therapy for the reduction of blood pressure (BP) in patients with hypertension.

\begin{abstract}
METHODS
Search strategy

All prospective randomized controlled trials of azilsartan therapy enrolling patients with hypertension were identified using a two-level search strategy. First, MEDLINE, EMBASE and the Cochrane Central Register of Controlled Trials were searched from the beginning of the records through March 2013 using web-based search engines (PubMed and OVID). Second, relevant studies were identified by manually searching secondary sources, including reference lists in the initially identified articles and a search of reviews and commentaries. Keywords included 'azilsartan' and ('randomized' or 'randomly' or 'randomization'). All references were downloaded for consolidation, elimination of duplicates and further analysis.
\end{abstract}

Study selection and data abstraction

Studies considered for inclusion met the following criteria: the design was a prospective randomized controlled clinical trial; the study population included patients with hypertension; patients were randomly assigned to azilsartan (including azilsartan medoxomil) vs. any control therapy; and the main outcomes included clinic BP or 24-h mean BP by ambulatory BP monitoring (ABPM). Data regarding detailed inclusion criteria, duration of follow-up and clinic BP or 24-h mean BP were abstracted (as available) from each individual study. 


\section{Statistical analysis}

We conducted a meta-analysis of summary statistics from the individual trials because detailed, patient-level data were not available for all of the trials. For each study, data for the changes from baseline to final systolic BP and diastolic BP (SBP and DBP) in both the azilsartan group and the control group were used to generate mean differences (MDs) and 95\% confidence intervals (CIs). When an $\mathrm{MD}$ of $\mathrm{BP}$ changes in the two groups itself was reported, we directly extracted it with its $95 \%$ CI. A missing s.d. was imputed according to the Cochrane Handbook. ${ }^{3}$ Study-specific estimates were combined in the randomeffects model. To assess the impact of azilsartan dosage on the pooled estimate, the effects of azilsartan therapy on BP were explored separately in the comparison of 20,40 and $80 \mathrm{mg}$ azilsartan with control therapy (primary meta-analysis). Between-study heterogeneity was analyzed using standard $\chi^{2}$ tests. Sensitivity analyses were performed to assess the contribution of each study to the pooled estimate by excluding individual trials one at a time and recalculating the pooled $\mathrm{MD}$ estimates for the remaining studies. Publication bias was assessed graphically using a funnel plot and mathematically using a linear regression test, according to the method of Egger et al. ${ }^{4}$ All analyses were conducted using Review Manager version 5.1 (Nordic Cochrane Centre, Copenhagen, Denmark) and Comprehensive Meta-Analysis version 2 software (Biostat, Englewood, NJ, USA)

\section{RESULTS}

Search results

Of 27 potentially relevant articles screened initially, 7 reports of prospective randomized controlled clinical trials of azilsartan or azilsartan medoxomil therapy, enrolling a total of 6152 patients with hypertension, were identified and included (Table 1). ${ }^{5-11}$ These included five ARB-controlled trials (olmesartan, ${ }^{5,11}$ olmesartan plus hydrochlorothiazide ( $v s$. azilsartan medoxomil plus chlorthalidone), ${ }^{7}$ candesartan, ${ }^{8}$ valsartan $\left.{ }^{9,11}\right)$, one ramipril-controlled trial $^{6}$ and one chlorthalidone-controlled trial. ${ }^{10}$ The articles included one comparison with $20 \mathrm{mg}$ azilsartan medoxomil, ${ }^{5}$ six comparisons with $40 \mathrm{mg}$ azilsartan medoxomil (including one comparison with $40 \mathrm{mg}$ $\left.\operatorname{azilsartan}^{8}\right)^{5-9,11}$ and six comparisons with $80 \mathrm{mg}$ azilsartan medoxomil. ${ }^{5-7,9-11}$ A factorial study by Sica et al. ${ }^{10}$ included 20, 40 and $80 \mathrm{mg}$ azilsartan medoxomil and 12.5 and $25 \mathrm{mg}$ chlorthalidone groups. However, we were able to abstract both the mean and s.d. of BP changes from only the $80 \mathrm{mg}$ azilsartan medoxomil and $25 \mathrm{mg}$ chlorthalidone groups. The duration of treatment varied from 6 to 24 weeks. Despite the noted heterogeneity in design between the trials, there was sufficient similarity between the populations and the hypotheses to merit inclusion of all seven trials in the quantitative meta-analysis. The most dissimilar trials (the trial by Rakugi et al. ${ }^{8}$ of azilsartan [not azilsartan medoxomil] therapy; and the chlorthalidonecontrolled trial by Sica et al..$^{10}$ ) were sequentially eliminated in sensitivity analyses that assessed the impact on the pooled effect estimate.

Primary meta-analysis

Pooled analysis demonstrated a statistically significant $4.20 / 2.58 \mathrm{~mm} \mathrm{Hg}$ reduction in clinic SBP/DBP with $40 \mathrm{mg}$ azilsartan (MD for SBP: $-4.20 \mathrm{~mm} \mathrm{Hg}$; $95 \%$ CI: -6.05 to $-2.35 \mathrm{~mm} \mathrm{Hg} ; \quad P$ for effect $<0.00001 ; P$ for heterogeneity $=0.0003$; Figure 1a; MD for DBP:

Table 1 Trial characteristics

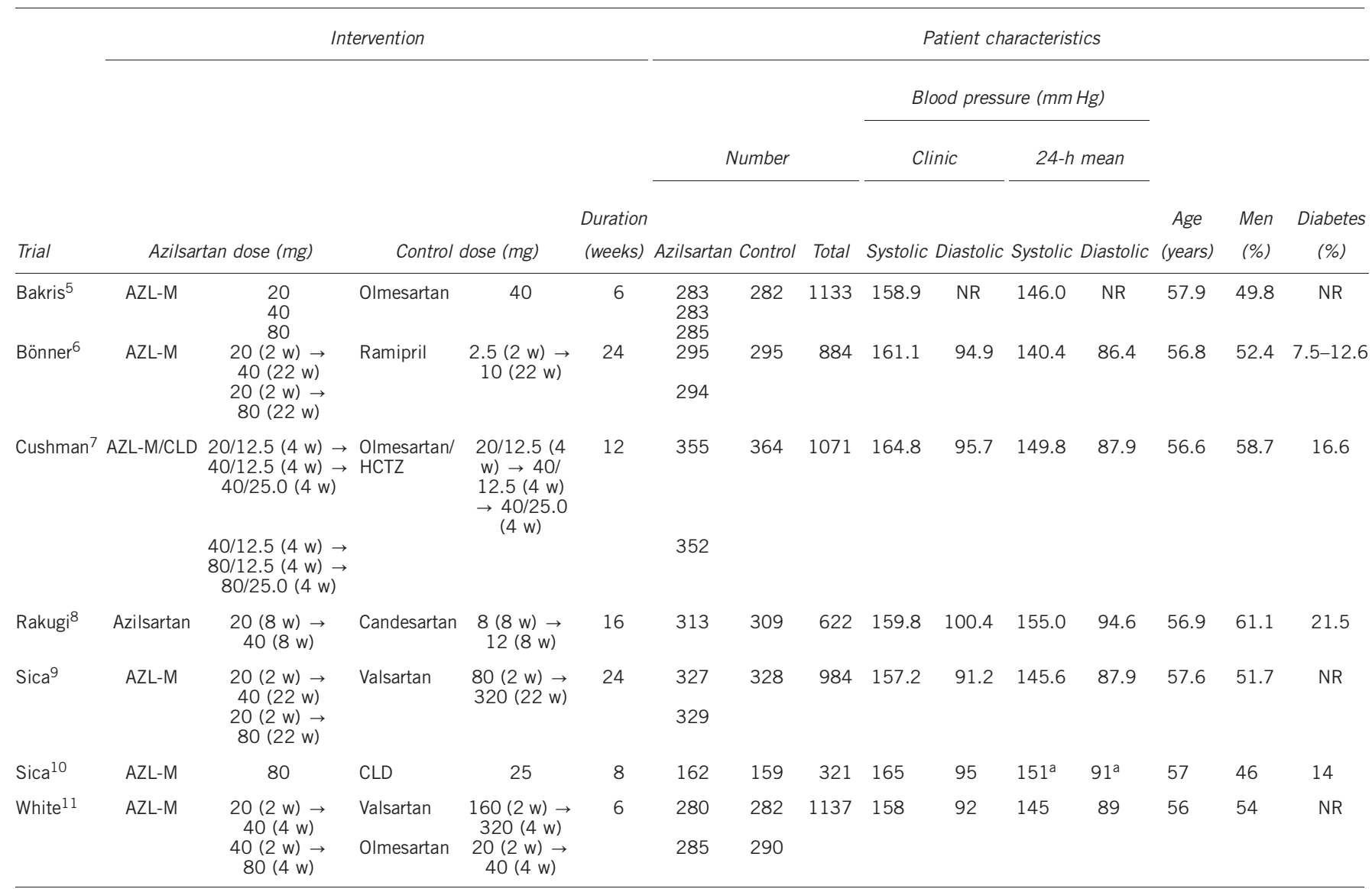

Abbreviations: AZL-M, azilsartan medoxomil; BP, blood pressure; CLD; chlorthalidone; HCTZ, hydrochlorothiazide; NR, not reported.

aTrough (hours 22 to 24 after dosing) blood pressure as determined by ambulatory blood pressure monitoring. 
$-2.58 \mathrm{~mm} \mathrm{Hg} ; 95 \%$ CI: -3.69 to $-1.48 \mathrm{~mm} \mathrm{Hg} ; \quad P$ for effect $<0.00001$; $P$ for heterogeneity $=0.008$; Figure $1 \mathrm{~b}$ ) and a $4.37 / 3.56 \mathrm{~mm}$ $\mathrm{Hg}$ reduction with $80 \mathrm{mg}$ azilsartan (MD for SBP: $-4.37 \mathrm{~mm} \mathrm{Hg}$; $95 \%$ CI: -7.01 to $-1.73 \mathrm{~mm} \mathrm{Hg}$; $P$ for effect $=0.001 ; P$ for heterogeneity $<0.00001$; Figure 1a; MD for DBP: $-3.56 \mathrm{~mm} \mathrm{Hg}$; $95 \% \mathrm{CI}:-4.69$ to $-2.43 \mathrm{~mm} \mathrm{Hg} ; \quad P$ for effect $<0.00001 ; P$ for heterogeneity $=0.03$; Figure $1 \mathrm{~b}$ ) relative to control therapy. When the 24-h mean BP data from ABPM were pooled, the 40 and $80 \mathrm{mg}$ azilsartan therapeutic regimens were significantly associated with reductions in SBP/DBP relative to control therapy of, respectively, $3.33 / 2.12 \mathrm{~mm} \mathrm{Hg}$ (MD for SBP: $-3.33 \mathrm{~mm} \mathrm{Hg}$; $95 \% \mathrm{CI}$ : -4.74 to $-1.93 \mathrm{~mm} \mathrm{Hg}$; $P$ for effect $<0.00001$; $P$ for heterogeneity $=0.005$; Figure $2 \mathrm{a}$; MD for DBP: $-2.12 \mathrm{~mm} \mathrm{Hg} ; 95 \%$ CI: -2.74 to $-1.49 \mathrm{~mm} \mathrm{Hg} ; \quad P$ for effect $<0.00001$; $P$ for heterogeneity $=0.28$; Figure $2 \mathrm{~b}$ ) and $3.70 / 2.86 \mathrm{~mm} \mathrm{Hg}$ (MD for SBP: $-3.70 \mathrm{~mm} \mathrm{Hg}$; $95 \% \mathrm{CI}:-5.70$ to $-1.69 \mathrm{~mm} \mathrm{Hg}$; $P$ for effect $=0.0003$; $P$ for heterogeneity $<0.0001$; Figure $2 \mathrm{a}$; MD for DBP:

a

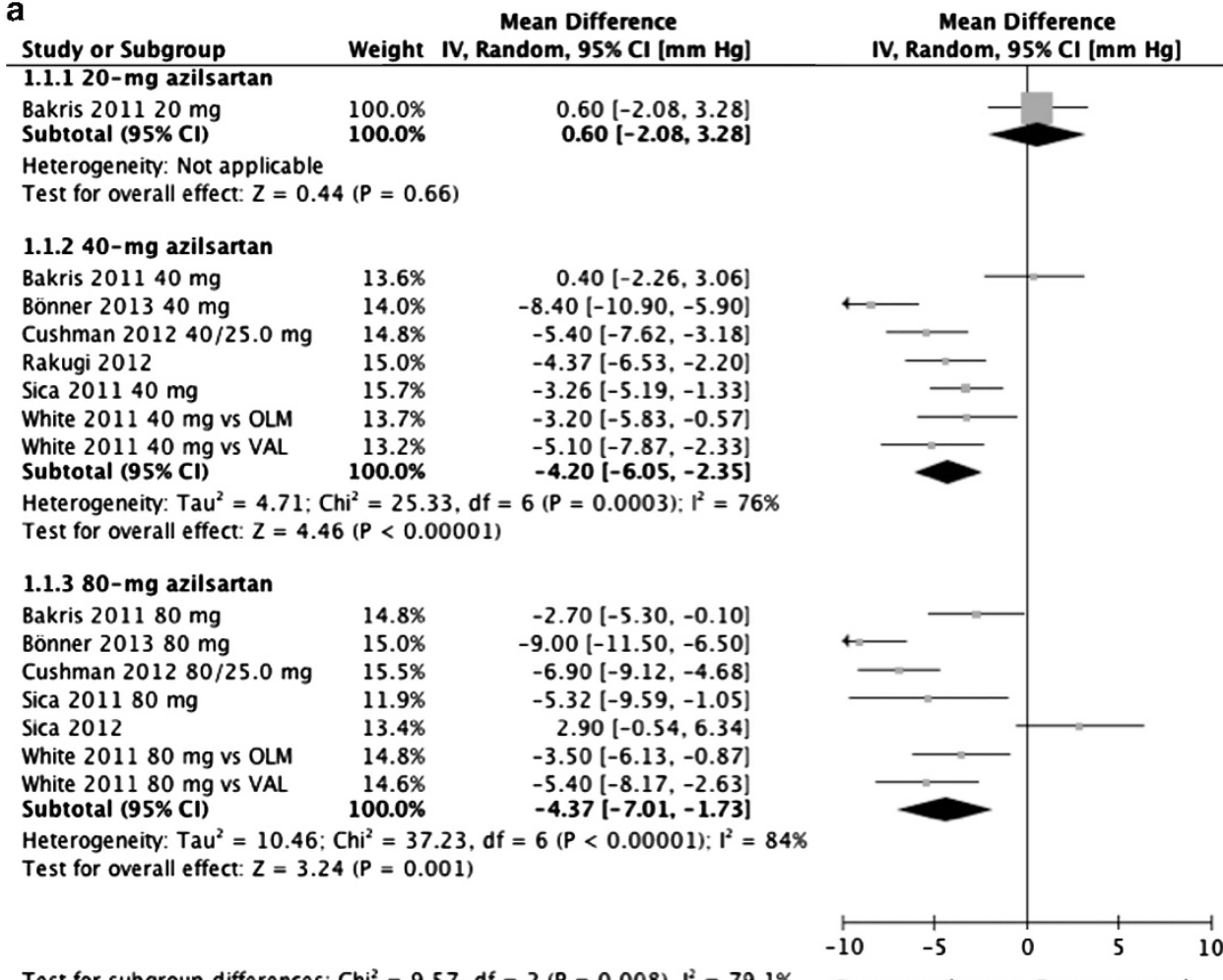

Test for subgroup differences: $\mathrm{Chi}^{2}=9.57, \mathrm{df}=2(\mathrm{P}=0.008), \mathrm{I}^{2}=79.1 \%$

Favours azilsartan Favours control

b

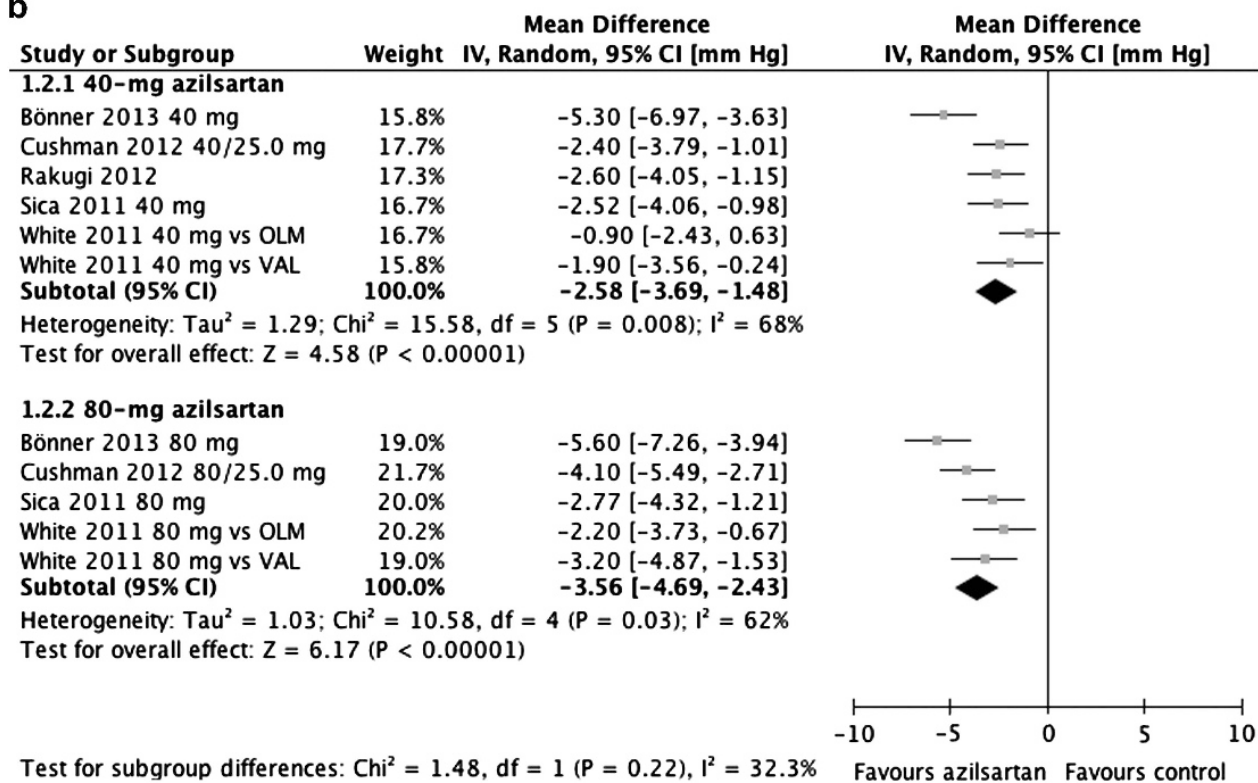

Figure 1 Forest plot of clinic systolic (a) and diastolic (b) blood pressure changes among hypertensive patients randomized to azilsartan vs. control therapy according to treatment dosage. $\mathrm{Cl}$, confidence interval; IV, inverse variance. A full color version of this figure is available at the Hypertension Research journal online. 
a

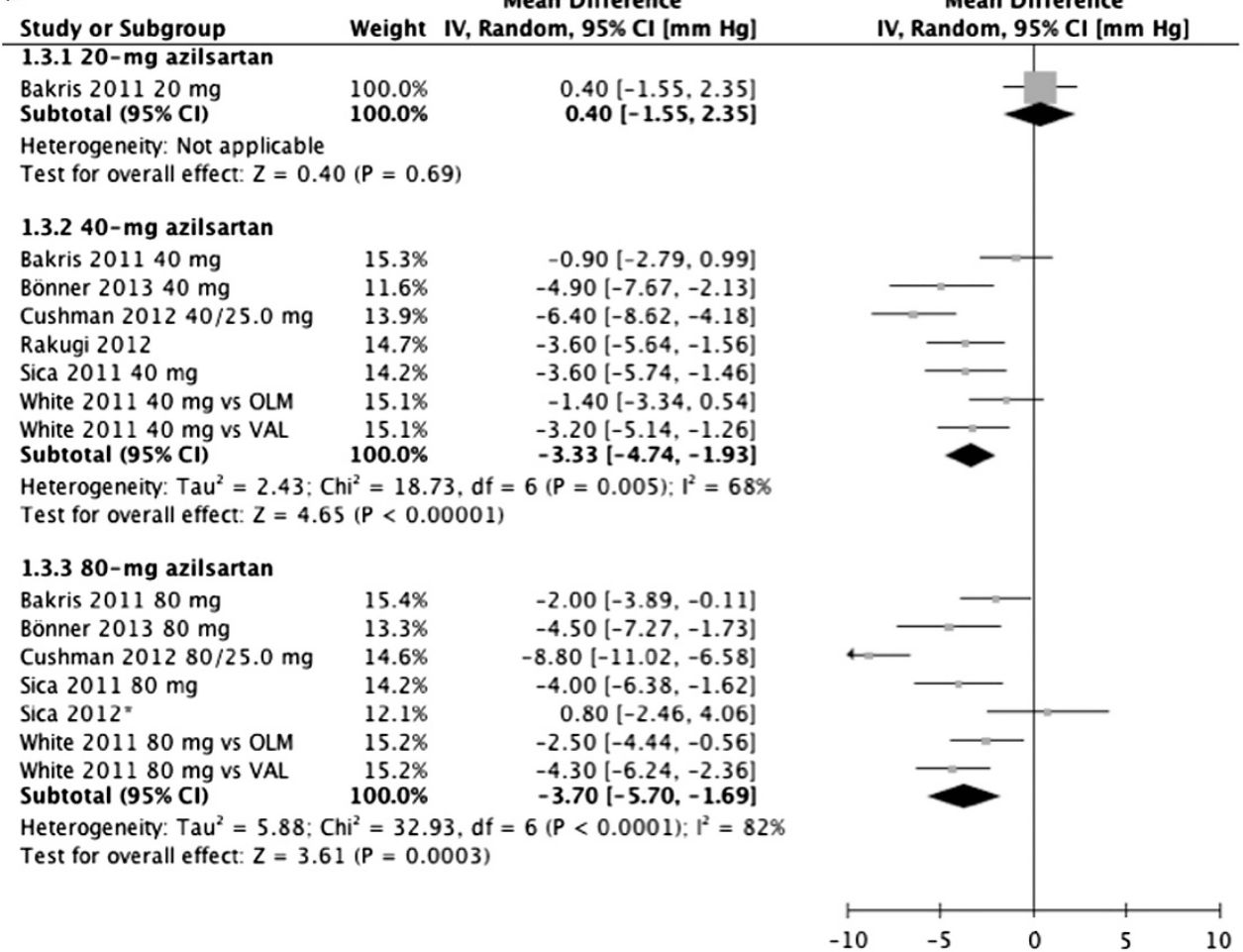

Test for subgroup differences: $\mathrm{Chi}^{2}=11.24, \mathrm{df}=2(\mathrm{P}=0.004), \mathrm{I}^{2}=82.2 \%$

Favours azilsartan Favours control

b

\begin{tabular}{|c|c|c|c|c|}
\hline \multirow{2}{*}{$\begin{array}{l}\text { Study or Subgroup } \\
1.4 .140-\mathrm{mg} \text { azilsartan }\end{array}$} & Weight & \multirow[t]{2}{*}{$\begin{array}{c}\text { Mean Difference } \\
\text { IV, Random, } 95 \% \mathrm{CI}[\mathrm{mm} \mathrm{Hg}]\end{array}$} & \multicolumn{2}{|c|}{$\begin{array}{c}\text { Mean Difference } \\
\text { IV, Random, } 95 \% \mathrm{CI}[\mathrm{mm} \mathrm{Hg}]\end{array}$} \\
\hline & & & & \\
\hline Bönner $201340 \mathrm{mg}$ & $9.3 \%$ & $-2.70[-4.64,-0.76]$ & & \\
\hline Cushman $201240 / 25.0 \mathrm{mg}$ & $19.3 \%$ & $-3.20[-4.45,-1.95]$ & -- & \\
\hline Rakugi 2012 & $19.6 \%$ & $-2.10[-3.34,-0.86]$ & - - & \\
\hline Sica $201140 \mathrm{mg}$ & $18.7 \%$ & $-2.16[-3.44,-0.88]$ & - & \\
\hline White $201140 \mathrm{mg}$ vs OLM & $16.5 \%$ & $-1.00[-2.39,0.39]$ & & \\
\hline $\begin{array}{l}\text { White } 201140 \mathrm{mg} \text { vs VAL } \\
\text { Subtotal }(95 \% \mathrm{Cl})\end{array}$ & $\begin{array}{r}16.5 \% \\
100.0 \%\end{array}$ & $\begin{array}{l}-1.60[-2.99,-0.21] \\
-2.12[-2.74,-1.49]\end{array}$ & 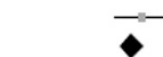 & \\
\hline \multicolumn{5}{|c|}{$\begin{array}{l}\text { Heterogeneity: } \text { Tau }^{2}=0.12 ; \mathrm{Chi}^{2}=6.24, \mathrm{df}=5(\mathrm{P}=0.28) ; \mathrm{I}^{2}=20 \% \\
\text { Test for overall effect: } Z=6.60(P<0.00001)\end{array}$} \\
\hline \multicolumn{5}{|l|}{ 1.4.2 80-mg azilsartan } \\
\hline Bönner $201380 \mathrm{mg}$ & $15.9 \%$ & $-3.00[-4.81,-1.19]$ & 一- & \\
\hline Cushman $201280 / 25.0 \mathrm{mg}$ & $21.9 \%$ & $-4.50[-5.75,-3.25]$ & - & \\
\hline Sica $201180 \mathrm{mg}$ & $21.4 \%$ & $-2.69[-3.99,-1.40]$ & - & \\
\hline White $201180 \mathrm{mg}$ vs OLM & $20.4 \%$ & $-1.70[-3.09,-0.31]$ & $-=$ & \\
\hline $\begin{array}{l}\text { White } 201180 \mathrm{mg} \text { vs VAL } \\
\text { Subtotal }(95 \% \mathrm{CI})\end{array}$ & $\begin{array}{r}20.4 \% \\
100.0 \%\end{array}$ & $\begin{array}{l}-2.30[-3.69,-0.91] \\
-2.86[-3.85,-1.86]\end{array}$ & - - & \\
\hline \multicolumn{5}{|c|}{$\begin{array}{l}\text { Heterogeneity: } \text { Tau }^{2}=0.76 ; \mathrm{Chi}^{2}=9.95, \mathrm{df}=4(\mathrm{P}=0.04) ; \mathrm{I}^{2}=60 \% \\
\text { Test for overall effect: } Z=5.64(\mathrm{P}<0.00001)\end{array}$} \\
\hline
\end{tabular}

Test for subgroup differences: $\mathrm{Chi}^{2}=1.53, \mathrm{df}=1(\mathrm{P}=0.22), \mathrm{I}^{2}=34.5 \%$

Favours azilsartan Favours control

Figure 2 Forest plot of 24-h mean systolic (a) and diastolic (b) blood pressure changes (as assessed by ambulatory blood pressure monitoring) among hypertensive patients randomized to azilsartan vs. control therapy according to treatment dosage. $\mathrm{Cl}$, confidence interval; IV, inverse variance. A full color version of this figure is available at the Hypertension Research journal online.

$-2.86 \mathrm{~mm} \mathrm{Hg} ; 95 \%$ CI: -3.85 to $-1.86 \mathrm{~mm} \mathrm{Hg} ; \quad P$ for effect $<0.00001$; $P$ for heterogeneity $=0.04$; Figure $2 b$ ).

\section{Sensitivity analyses}

To assess the impact of qualitative heterogeneity in trial design and patient selection on the pooled effect estimate, we performed several sensitivity analyses. First, we excluded the trial by Rakugi et al. ${ }^{8}$ of $40 \mathrm{mg}$ azilsartan (not azilsartan medoxomil) therapy; combining the remaining trials generated a still statistically significant result favoring $40 \mathrm{mg}$ azilsartan medoxomil therapy (MD for clinic SBP: $-4.17 \mathrm{~mm} \mathrm{Hg} ; 95 \%$ CI: -6.40 to $-1.95 \mathrm{~mm} \mathrm{Hg} ; \quad P$ for effect $=0.0002 ; P$ for heterogeneity $=0.0001$; MD for clinic DBP: $-2.58 \mathrm{~mm} \mathrm{Hg}$; $95 \% \mathrm{CI}$ : -3.95 to $-1.21 \mathrm{~mm} \mathrm{Hg} ; P$ for effect $=$ $0.0002 ; P$ for heterogeneity $=0.004 ; \mathrm{MD}$ for 24 -h mean SBP: $-3.30 \mathrm{~mm} \mathrm{Hg} ; 95 \%$ CI: -4.97 to $-1.64 \mathrm{~mm} \mathrm{Hg} ; \quad P$ for effect $<0.0001 ; P$ for heterogeneity $=0.002$; MD for 24 -h mean DBP: 
$-2.12 \mathrm{~mm} \mathrm{Hg} ; 95 \%$ CI: -2.91 to $-1.33 \mathrm{~mm} \mathrm{Hg} ; \quad P$ for effect $<0.00001$; $P$ for heterogeneity $=0.18$ ). Second, we excluded the chlorthalidone-controlled trial by Sica et al. ${ }^{10}$ Without it, there was still a statistically significant benefit for $80 \mathrm{mg}$ azilsartan therapy in a pooled analysis of the remaining trials $\mathrm{MD}$ for clinic SBP: $-5.52 \mathrm{~mm} \mathrm{Hg} ; 95 \%$ CI: -7.49 to $-3.54 \mathrm{~mm} \mathrm{Hg} ; P$ for effect $<0.00001 ; P$ for heterogeneity $=0.008$; MD for 24 -h mean SBP: $-4.31 \mathrm{~mm} \mathrm{Hg} ; 95 \% \mathrm{CI}:-6.26$ to $-2.35 \mathrm{~mm} \mathrm{Hg}$; $P$ for effect $<0.0001 ; P$ for heterogeneity $=0.0002$ ). In general, exclusion of any single trial from the analysis did not substantively alter the overall results of our analysis.

\section{Publication bias}

To assess publication bias, we generated a funnel plot of the effect size $v s$. the standard error for each trial (data not shown). There was no evidence of significant publication bias $(P=0.95375,0.47198,0.10486$ and 0.96909 for clinic SBP, clinic DBP, 24-h mean SBP and 24-h mean DBP with $40 \mathrm{mg}$ azilsartan therapy, respectively; $P=0.27557,0.83708$, 0.79346 and 0.63585 for clinic SBP, clinic DBP, 24-h mean SBP and 24-h mean DBP with $80 \mathrm{mg}$ azilsartan therapy, respectively; by Egger's linear regression test).

\section{DISCUSSION}

The results of our analysis suggest that azilsartan therapy may reduce clinic BP (by 4.20/2.58 and 4.37/3.56 $\mathrm{mm} \mathrm{Hg}$ in SBP/DBP with 40 and $80 \mathrm{mg}$ azilsartan, respectively) and 24-h mean BP as assessed by ABPM (by $3.33 / 2.12$ and $3.70 / 2.86 \mathrm{~mm} \mathrm{Hg}$ in SBP/DBP with 40 and $80 \mathrm{mg}$ azilsartan, respectively) more than control therapy in patients with hypertension. These results were robust in sensitivity analyses. Azilsartan binds tightly to, and dissociates slowly from, AT1 compared with other ARBs. ${ }^{2}$ In addition, azilsartan induces insurmountable antagonism of angiotensin II-induced vascular contractions and inverse agonism against AT1. The high-affinity and tight binding properties of azilsartan are expected to induce potent and long-lasting antihypertensive effects in preclinical and clinical settings. ${ }^{2}$

A unique feature of the azilsartan medoxomil clinical studies is the use of 24-h mean ${ }^{5,9,11}$ (or trough ${ }^{10}$ ) BP as assessed by ABPM as the primary efficacy measurement to evaluate the comparative effects of azilsartan medoxomil with other antihypertensives. ${ }^{12}$ There are theoretical advantages to using ABPM to assess a new antihypertensive drug. First, ABPM is superior in assessing the troughto-peak ratio of antihypertensive medications compared with clinic $\mathrm{BP}^{13}$ and has been shown to be a more reliable predictor of cardiovascular outcomes compared with traditional clinic or office BP readings. ${ }^{14,15}$ Second, using ABPM-derived values both as inclusion criteria as well as for end point evaluation avoids the inclusion of patients with proposed white-coat hypertension, which can skew clinic $\mathrm{BP}$ readings in clinical trials. ${ }^{12}$ Finally, ABPM produces lower variance with repeated studies compared with clinic BP measures ${ }^{16,17}$ and, from a clinical trials standpoint, allows for lower numbers of patients to be required to show the desired effect size of the drug under study. ${ }^{12}$

In addition to effects on BP in adults with hypertension, azilsartan medoxomil has shown beneficial effects on the cellular mechanisms of cardiovascular disease and insulin sensitivity in several animal studies and cellular experiments. ${ }^{1}$ Azilsartan medoxomil reduces the expression of plasminogen activator inhibitor type-1 in the plasma, left ventricle and aorta of mice rendered overexpressers of plasminogen activator inhibitor type-1 or ApoE deficient. ${ }^{18}$ It favorably modifies atherosclerotic lesions, as reflected by increased cellularity per lesion area and a trend toward increased collagen, consistent with the evolution of biologically stable rather than biologically unstable atherosclerotic plaques. Azilsartan medoxomil also diminishes plasminogen activator inhibitor type-1 expression in the left ventricular wall, potentially diminishing the likelihood of a robust fibrotic response after insults such as acute myocardial infarction. ${ }^{18}$ Further, azilsartan is a pleiotropic ARB with antiproliferative effects in vascular cells, and these effects may not strictly depend on AT1 blockade. ${ }^{19}$ Azilsartan, but not valsartan, blocks the angiotensin II-induced activation of mitogen-activated protein kinase in vascular smooth muscle cells long after drug washout from the incubation media. Azilsartan promotes adipocyte differentiation to a greater extent than valsartan and exerts stimulatory effects on the expression of genes for peroxisome proliferator-activated receptor (PPAR)- $\alpha$, PPAR- $\delta$, leptin, adipsin and adiponectin, whereas valsartan does not. ${ }^{19}$ These effects on adipocyte differentiation and gene expression are observed at concentrations of azilsartan that do not classically activate PPAR activity in cell-based transactivation assays. Furthermore, treatment with azilsartan improves glucose metabolism in obese spontaneously hypertensive Koletsky $\left(f a^{k} / f a^{k}\right)$ rats (carrying a nonsense mutation in the leptin receptor and exhibiting hyperphagia, obesity, hyperinsulinemia/insulin resistance and hyperlipidemia). ${ }^{20}$ This insulinsensitizing effect is independent of decreases in food intake and body weight increase or of the activation of PPAR- $\gamma$ in adipose tissue. By contrast, telmisartan prevents adipogenesis and weight gain through activation of PPAR- $\gamma$-dependent lipolytic pathways and energy uncoupling in several tissues. ${ }^{21}$ Candesartan therapy in hypertensive patients reverses endothelial dysfunction, measured as an improvement in flow-mediated dilation and fibrinolysis and reduction of oxidative stress and inflammatory cytokines independent of BP changes, suggesting that candesartan therapy has antiatherogenic effects. $^{22}$ Regarding pleiotropic effect-related parameters, urinary 8-isoprostane, fasting serum insulin and homeostasis model assessment of insulin resistance index are more suppressed after treatment with irbesartan than after candesartan and valsartan therapy. The maximum area under the curve and trough values of receptor occupancy significantly differ between irbesartan, valsartan and candesartan and are negatively correlated with the change in urinary 8 -isoprostane but not markers of insulin resistance. ${ }^{23}$

Our analysis must be viewed in the context of its limitations. First, a major limitation of all the included trials is their short duration of study ( $\leqslant 24$ weeks), which makes it difficult to capture long-term benefits and side effects associated with azilsartan therapy. ${ }^{24}$

Second, the possible role of azilsartan in preventing mortality and cardiovascular morbidity was not assessed. Even a $2-\mathrm{mm} \mathrm{Hg}$ lower SBP, however, can lead to an approximately $10 \%$ lower stroke mortality rate and an approximately $7 \%$ lower mortality rate from ischemic heart disease or other vascular causes in middle age. ${ }^{25}$ Further, a 2-mm Hg reduction in DBP has been shown to result in a $17 \%$ decrease in the prevalence of hypertension as well as a $6 \%$ reduction in the risk of coronary heart disease and a $15 \%$ reduction in the risk of stroke and transient ischemic attacks. ${ }^{26}$ Thus, the $\geqslant 4 / \geqslant 3$ $\mathrm{mm} \mathrm{Hg}$ reduction in clinic SBP/DBP with $80 \mathrm{mg}$ azilsartan relative to control therapy demonstrated in the present meta-analysis would be expected to provide clinical benefits in hypertensive patients.

Third, there has been no telmisartan-controlled trial. The results of our recent overview ${ }^{27}$ suggest that telmisartan therapy reduces SBP/ DBP by $2.20 / 1.54 \mathrm{~mm} \mathrm{Hg}$ over other ARB therapies. In the subgroup analyses, telmisartan therapy was effective in $\mathrm{BP}$ reduction relative to losartan or valsartan therapy. With respect to eprosartan, irbesartan or olmesartan therapy, the results of their comparisons with telmisartan therapy were inconclusive because of the very low 
numbers of included trials. Meanwhile, the BP-reduction capability of telmisartan is likely comparable to that of candesartan (telmisartan vs. candesartan; MD for SBP: $-0.66 \mathrm{~mm} \mathrm{Hg} ; 95 \% \mathrm{CI}:-4.24$ to $2.92 \mathrm{~mm} \mathrm{Hg}$; $P$ for effect $=0.72$; MD for DBP: $-1.07 \mathrm{~mm} \mathrm{Hg} ; 95 \%$ CI: -4.50 to $2.36 \mathrm{~mm} \mathrm{Hg}$; $P$ for effect $=0.54) .{ }^{27}$ As only one trial of azilsartan $v s$. candesartan therapy ${ }^{8}$ demonstrated a statistically significant $4.37 / 2.60-\mathrm{mm} \mathrm{Hg}$ reduction in clinic SBP/DBP and a $3.60 / 2.10-\mathrm{mm} \mathrm{Hg}$ reduction in 24-h mean SBP/DBP with $40 \mathrm{mg}$ azilsartan relative to $12 \mathrm{mg}$ candesartan, azilsartan therapy may be more effective in BP reduction than telmisartan therapy.

Forth, we used only data from randomized controlled trials. Patients enrolled in randomized trials may not be representative of patients typically observed in clinical practice. However, because randomized trials balance both known and unknown confounders across treatment groups, this is the study design least vulnerable to bias. Notable exclusion criteria from each of the azilsartan trials included patients with a history of major cardiovascular events or significant cardiac conduction abnormalities, severe renal impairment, or type 1 or poorly controlled type 2 diabetes. Thus, the results of the present meta-analysis cannot be applied directly to these populations. This is particularly important because many patients with hypertension requiring large reductions in SBP to achieve their desired goal have cardiovascular disease, and efficacy and safety data for azilsartan are lacking in these populations. ${ }^{12}$

Fifth, our results may have been influenced by a publication bias favoring azilsartan, which was marketed more recently than the control ARBs (olmesartan, $5,7,11$ candesartan ${ }^{8}$ and valsartan ${ }^{9,11}$ ). This risk was minimized through an exhaustive search of the available literature. Although the statistical tests did not indicate publication bias, there is clearly limited power to detect such bias, given the relatively small number of studies examined.

Finally, we used the random-effects rather than fixed-effects estimate as the summary measure. To calculate a CI for a fixedeffects meta-analysis, the assumption is made that the true effect of intervention (in both magnitude and direction) is the same value in every study (that is, fixed across studies), which implies that the observed differences among study results are due solely to chance, that is, that there is no statistical heterogeneity. ${ }^{28}$ When there is heterogeneity that cannot readily be explained, one analytical approach is to incorporate it into a random-effects model. For any particular set of studies in which heterogeneity is present, a CI around the random-effects pooled estimate is wider than a CI around a fixedeffects pooled estimate. ${ }^{28}$ To make a more conservative evaluation, we used the random-effects rather than fixed-effects model despite the presence or absence of between-study heterogeneity of results using standard $\chi^{2}$ tests.

In conclusion, despite these acknowledged limitations, our metaanalysis indicates that azilsartan therapy is likely more effective at reducing clinic and 24-h mean BP than control therapy in patients with hypertension.

\section{CONFLICT OF INTEREST}

The authors declare no conflict of interest.

1 Perry CM. Azilsartan medoxomil: a review of its use in hypertension. Clin Drug Investig 2012; 32: 621-639.

2 Ojima M, Igata $H$, Tanaka M, Sakamoto $H$, Kuroita T, Kohara $Y$, Kubo K, Fuse $H$, Imura $\mathrm{Y}$, Kusumoto $\mathrm{K}$, Nagaya $\mathrm{H}$. In vitro antagonistic properties of a new angiotensin type 1 receptor blocker, azilsartan, in receptor binding and function studies. J Pharmacol Exp Ther 2011; 336: 801-808.
3 Higgins JP, Deeks JJ and Altman DG (eds). Special topics in statistics. In: Higgins JP and Green S (eds), Cochrane Handbook for Systematic Reviews of Interventions, Chapter 16, Version 5.1 .0 (updated March 2011). The Cochrane Collaboration, 2011, Available from http://www.cochrane-handbook.org.

4 Egger M, Davey Smith G, Schneider M, Minder C. Bias in meta-analysis detected by a simple, graphical test. BMJ 1997; 315: 629-634.

5 Bakris GL, Sica D, Weber M, White WB, Roberts A, Perez A, Cao C, Kupfer S. The comparative effects of azilsartan medoxomil and olmesartan on ambulatory and clinic blood pressure. J Clin Hypertens (Greenwich) 2011; 13: 81-88.

6 Bönner G, Bakris GL, Sica D, Weber MA, White WB, Perez A, Cao C, Handley A, Kupfer $\mathrm{S}$. Antihypertensive efficacy of the angiotensin receptor blocker azilsartan medoxomil compared with the angiotensin-converting enzyme inhibitor ramipril. J Hum Hypertens 2013; 27: 479-486.

7 Cushman WC, Bakris GL, White WB, Weber MA, Sica D, Roberts A, Lloyd E, Kupfer S. Azilsartan medoxomil plus chlorthalidone reduces blood pressure more effectively than olmesartan plus hydrochlorothiazide in stage 2 systolic hypertension. Hypertension 2012; 60: 310-318.

8 Rakugi H, Enya K, Sugiura K, Ikeda Y. Comparison of the efficacy and safety of azilsartan with that of candesartan cilexetil in Japanese patients with grade I-II essential hypertension: a randomized, double-blind clinical study. Hypertens Res 2012; 35: 552-558.

9 Sica D, White WB, Weber MA, Bakris GL, Perez A, Cao C, Handley A, Kupfer S. Comparison of the novel angiotensin II receptor blocker azilsartan medoxomil vs. valsartan by ambulatory blood pressure monitoring. J Clin Hypertens (Greenwich) 2011; 13: 467-472.

10 Sica D, Bakris GL, White WB, Weber MA, Cushman WC, Huang P, Roberts A, Kupfer S. Blood pressure-lowering efficacy of the fixed-dose combination of azilsartan medoxomil and chlorthalidone: a factorial study. J Clin Hypertens (Greenwich) 2012; 14 : 284-292.

11 White WB, Weber MA, Sica D, Bakris GL, Perez A, Cao C, Kupfer S. Effects of the angiotensin receptor blocker azilsartan medoxomil versus olmesartan and valsartan on ambulatory and clinic blood pressure in patients with stages 1 and 2 hypertension. Hypertension 2011; 57: 413-420.

12 Baker WL, White WB. Azilsartan medoxomil: a new angiotensin II receptor antagonist for treatment of hypertension. Ann Pharmacother 2011; 45: 1506-1515.

13 White WB. Relating cardiovascular risk to out-of-office blood pressure and the importance of controlling blood pressure 24 hours a day. Am J Med 2008; 121 (8 Suppl), S2-S7.

14 Fagard RH, Thijs L, Staessen JA, Clement DL, De Buyzere ML, De Bacquer DA. Prognostic significance of ambulatory blood pressure in hypertensive patients with history of cardiovascular disease. Blood Press Monit 2008; 13: 325-332.

15 Dolan E, Stanton AV, Thom S, Caulfield M, Atkins N, McInnes G, Collier D, Dicker P, O'Brien EASCOT Investigators. Ambulatory blood pressure monitoring predicts cardiovascular events in treated hypertensive patients-an Anglo-Scandinavian cardiac outcomes trial substudy. J Hypertens 2009; 27: 876-885.

16 Mansoor GA, McCabe EJ, White WB. Long-term reproducibility of ambulatory blood pressure. J Hypertens 1994; 12: 703-708.

17 Campbell P, Ghuman N, Wakefield D, Wolfson L, White WB. Long-term reproducibility of ambulatory blood pressure is superior to office blood pressure in the very elderly. J Hum Hypertens 2010; 24: 749-754.

18 French CJ, Zaman AK, Sobel BE. The angiotensin receptor blocker, azilsartan medoxomil (TAK-491), suppresses vascular wall expression of plasminogen activator inhibitor type-I protein potentially facilitating the stabilization of atherosclerotic plaques. J Cardiovasc Pharmacol 2011; 58: 143-148.

19 Kajiya T, Ho C, Wang J, Vilardi R, Kurtz TW. Molecular and cellular effects of azilsartan: a new generation angiotensin II receptor blocker. J Hypertens 2011; 29: 2476-2483.

20 Zhao M, Li Y, Wang J, Ebihara K, Rong X, Hosoda K, Tomita T, Nakao K. Azilsartan treatment improves insulin sensitivity in obese spontaneously hypertensive Koletsky rats. Diabetes Obes Metab 2011; 13: 1123-1129.

$21 \mathrm{He} \mathrm{H}$, Yang D, Ma L, Luo Z, Ma S, Feng X, Cao T, Yan Z, Liu D, Tepel M, Zhu Z. Telmisartan prevents weight gain and obesity through activation of peroxisome proliferator-activated receptor-delta-dependent pathways. Hypertension 2010; 55: 869-879.

22 Koh KK, Ahn JY, Han SH, Kim DS, Jin DK, Kim HS, Shin MS, Ahn TH, Choi IS, Shin EK. Pleiotropic effects of angiotensin II receptor blocker in hypertensive patients. J Am Coll Cardiol 2003; 42: 905-910.

23 Ando H, Ushijima K, Hosohata K, Saito T, Fujimura A. Relationship between the receptor occupancy profile and pleiotropic effects of angiotensin II receptor blockers. Br J Clin Pharmacol 2013; 75: 415-422.

24 Lam S. Azilsartan: a newly approved angiotensin II receptor blocker. Cardiol Rev 2011; 19: 300-304.

25 Lewington S, Clarke R, Qizilbash N, Peto R, Collins R. Prospective Studies Collaboration. Age-specific relevance of usual blood pressure to vascular mortality: a metaanalysis of individual data for one million adults in 61 prospective studies. Lancet 2002; 360: 1903-1913.

26 Cook NR, Cohen J, Hebert PR, Taylor JO, Hennekens $\mathrm{CH}$. Implications of small reductions in diastolic blood pressure for primary prevention. Arch Intern Med 1995; 155: 701-709.

27 Takagi H, Niwa M, Mizuno Y, Goto SN, Umemoto T. A meta-analysis of randomized trials of telmisartan vs. valsartan therapy for blood pressure reduction. Hypertens Res 2013; 36: 627-633.

28 Deeks JJ, Higgins JP and Altman DG (eds). Analysing data and undertaking meta-analyses. In: Higgins JP and Green S (eds), Cochrane Handbook for Systematic Reviews of Interventions, Chapter 9, Version 5.1.0 (updated March 2011). The Cochrane Collaboration, 2011, Available from http://www.cochrane-handbook.org. 